\title{
Longitudinal analysis of quality of life in patients treated for differentiated thyroid cancer
}

\section{Evert F S van Velsen ${ }^{1}$, Elske T Massolt ${ }^{1,4}$, Hélène Heersema' ${ }^{1}$, Boen L R Kam² Tessa M van Ginhoven ${ }^{3}$, W Edward Visser ${ }^{1}$ and Robin P Peeters ${ }^{1}$}

Departments of ${ }^{1}$ Internal Medicine, ${ }^{2}$ Nuclear Medicine, ${ }^{3}$ Surgery, Academic Center for Thyroid Diseases, Erasmus Medical Center, Rotterdam, The Netherlands, and ${ }^{4}$ Department of Internal Medicine, Albert Schweitzer Hospital, Dordrecht, The Netherlands
Correspondence should be addressed to R P Peeters

Email

r.peeters@erasmusmc.nl

\begin{abstract}
Objective: Earlier cross-sectional studies showed that patients with differentiated thyroid cancer (DTC) have a significant reduction of quality of life (QoL) compared to controls. However, recent longitudinal studies showed mixed results and had relative short follow-up or lacked knowledge about QoL before initial surgery. Therefore, we initiated a longitudinal study to assess changes of QoL in patients undergoing treatment for DTC.

Methods: We prospectively included patients, aged 18-80 years, who were treated for DTC at a Dutch university hospital. Using questionnaires, QoL was assessed before surgery, just before radioiodine (RAI) therapy, and regularly during follow-up. Repeated measurement analysis was used to assess changes of QoL over time, and we explored the influence of different characteristics on QoL.

Results: Longitudinal QoL assessments were available in 185 patients (mean age 47 years; $71 \%$ women). All patients were treated according to the Dutch guidelines with total thyroidectomy followed by RAI ( $83 \%$ after thyroid hormone withdrawal). Median time between baseline and final questionnaire was 31 months, and patients completed a median of three questionnaires. QoL at baseline was lower than that in the general population, developed non-linear over time, was lowest around RAl therapy, and recovered over time. Females, younger patients, and patients with persistent hypoparathyroidism had lower QoL scores.

Conclusions: In a population of DTC patients, QoL before initial therapy is already lower than that in the general population. Thereafter, QoL develops non-linearly over time in general, with the lowest QoL around RAI therapy, while 2 to 3 years later, it approximates baseline values.
\end{abstract}

\section{Introduction}

The worldwide incidence of differentiated thyroid cancer (DTC) has been steadily increasing over the last two decades $(1,2)$. As patients with DTC have a relatively good prognosis in general $(3,4,5)$, treating these patients is a trade-off between gaining survival on one hand, and preserving quality of life (QoL) on the other hand. Therefore, a less aggressive therapeutic approach is suggested for selected populations $(6,7)$.

There are numerous questionnaires to measure QoL in patients with thyroid cancer, and the most commonly
European Journal of Endocrinology

(2019) 181, 671-679 used to assess general QoL is the Short-Form-36 (SF-36) $(8,9)$. Besides, thyroid-specific QoL can be assessed using the thyroid-specific patient-reported outcome measure (ThyPRO) questionnaire, which was earlier validated and subsequently used in patients with thyroid diseases $(10,11,12)$.

Several cross-sectional studies showed a decreased QoL in different domains in thyroid cancer survivors compared to the general population $(12,13,14,15$, $16,17)$. Additionally, their QoL is at the same level as 
in patients with other cancers with worse prognosis and is even worse than in breast cancer survivors (18). Main drawback of the aforementioned cross-sectional studies is that no conclusions can be drawn about QoL evolution over time. Therefore, more recently several longitudinal studies were conducted $(16,17,19,20,21)$. Their results were mixed as some showed increasing QoL $(16,20)$, and others showed decreasing QoL over time $(17,19)$. However, these longitudinal studies had one or more limitations such as relative short follow-up with a maximum of 2 years $(19,20,21)$ or lack of knowledge about QoL before initial surgery $(16,20)$. The aim of our study, lacking the above-mentioned limitations, was therefore to investigate long-term longitudinal changes of quality of life in patients undergoing treatment for differentiated thyroid cancer.

\section{Subjects and methods}

\section{Study population}

We aimed to include all patients, aged 18-80 years, who were treated for DTC at the Erasmus Medical Center, Rotterdam, The Netherlands. Inclusion period was from January 2013 until December 2017, and patients were followed for at least 1 year. All included patients had tumors $\geq 1 \mathrm{~cm}$ and were treated in line with the current Dutch guideline with a total thyroidectomy followed by RAI therapy (22). Further, included patients understood Dutch language and did not have any other active malignancy or an active inflammatory disease.

We recorded demographic, disease, and treatment characteristics. Demographical variables included age at diagnosis and gender. Disease characteristics included disease type, AJCC/TNM-stage (8th edition), and ATA Risk Stratification category (2015). Data regarding treatment consisted of extent of surgery, method of RAI preparation, number of RAI therapies, and cumulative RAI dose. RAI therapy was given either after 3-4 weeks of thyroid hormone withdrawal or after two subsequent injections with recombinant human TSH (rhTSH). Further, incidence of recurrent nerve paralysis and hypoparathyroidism was recorded.

At baseline, that is, before surgery, just before RAI therapy, 6-9 months later, and every 1-2 years thereafter, patients were asked to fill in three different QoL questionnaires (see next section for details). Additionally, if a patient received more than one RAI therapy, just before a new therapy, and 6 to 9 months thereafter additional questionnaires were handed-out; thereafter, the regular schedule was continued.

The study was approved by the Institutional Review Board of the Erasmus Medical Center, and consent has been obtained from each patient after full explanation of the purpose and procedures.

\section{Quality of life questionnaires}

The ThyPRO is a thyroid-specific QoL questionnaire which consists of 85 questions summarized in 13 scales (10). Scores vary from 0 to 100 with higher scores indicating more thyroid-related complaints. We used the Composite, Tiredness, Cognitive problems, Anxiety, Depressivity, Social Impairment, and Daylife Impairment scores (23).

The Multidimensional Fatigue Index-20 (MFI-20) is a 20 -item self-report instrument designed to assess fatigue (24). Scores vary from 0 to 20 with higher scores indicating more fatigue. We used the General, Physical and Mental Fatigue scores.

The RAND-36 item health survey (RAND-36) is the validated Dutch version of the $\operatorname{SF}-36(8,9,25)$. It is a generic questionnaire aimed at overall health-related QoL during the previous 30 days. It consists of nine subscales and two summary scales. Scores vary from 0 to 100 with higher scores associated with better QoL. We used the General Health, General Mental Health, Vitality, Physical functioning and Social functioning scores.

\section{Statistical analysis}

For continuous variables we calculated means and standard deviations (s.D.) or in case of a non-normal distribution, medians with interquartile ranges (IQR). For categorical variables, absolute numbers with percentages were recorded. In order to assess the changes of QoL over time while accounting for the correlation between the repeated measurements of each patient, we used marginal models; the appropriate random-effects structure that best fitted the data was selected. If needed, appropriate transformation of the QoL scores was applied to obtain a normal distribution. Further, using a marginal model allows QoL questionnaires to be collected without predefined time points and therewith strengthens the model creation and analysis. Additionally, this model enabled us to determine QoL at each moment in time. Our main analysis assessed changes in QoL over time. Further, additional analyses were performed to explore the effect of different factors on QoL over time; these factors were age ( $<50$ years vs $\geq 50$ years), sex, presence 
of permanent hypoparathyroidism, presence of recurrent nerve paralysis, ATA Risk Stratification category (low vs intermediate/high) or number of RAI therapies (single vs multiple). In general, $P$ values below 0.05 were considered significant. The age cut-off of 50 years was based on the age distribution of the population. The possibility of effect modification was studied using a two-step strategy. Firstly, a screening $P$ value cut-off for interaction of $<0.10$ was used, because the statistical power to identify an interaction term is less than that for normal covariates. Secondly, to make sure that we do not identify irrelevant modification, we subsequently performed stratified analyses to replicate and quantify the effect modification so that we can interpret whether the differences are of (clinical) relevance. All analyses were performed using either SPSS Statistics for Windows (version 24.0) or R statistical software (version 3.4.1).

\section{Results}

\section{Population characteristics}

During the study period, a total of 238 patients were eligible for the study of which 18 patients were not included because they either did not want to participate $(n=9)$ or were missed at inclusion $(n=9)$. Further, 35 patients completed less than two questionnaires and were subsequently removed from the analyses (see Supplementary Table 1 for their characteristics, see section on supplementary data given at the end of this article). Therefore, the analyses presented here were performed in the remaining 185 patients.

Table 1 lists the characteristics of the study population. Mean age was 47.0 years, and 131 (71\%) were women. Papillary thyroid carcinoma was present in $162(88 \%)$ patients, and the remaining 23 patients (12\%) had follicular thyroid carcinoma. Patients were almost equally distributed over the three ATA Risk categories. Total thyroidectomy was performed in all patients, and neck dissection in 70 (38\%) of them (central in 23 (12\%), lateral in one (1\%), and both in $46(25 \%))$. All patients underwent RAI therapy, of which 142 (77\%) received one therapy, while the others received two or more therapies. The majority (83\%) of the patients received their first RAI therapy after thyroid hormone withdrawal. Thirty-one patients (17\%) developed permanent hypoparathyroidism, while 17 patients (9\%) had a recurrent nerve paralysis at end of follow-up. Additionally, we found a significant correlation between permanent hypoparathyroidism and neck dissection ( $P$ value $<0.001)$; it is known that a neck dissection is a risk factor for permanent hypoparathyroidism (6). Median time between surgery and completing the final questionnaire was 31 months, and during follow-up, patients completed a median of three questionnaires.

\section{Quality of Life}

QoL at baseline and during follow-up for the different QoL scores is listed in Table 2. Further, we also compared our baseline QoL with reference values obtained from literature $(13,25,26)$. QoL at baseline in patients was lower than that in the general population for all scores, except for the ThyPRO Cognitive Problems score.

The ThyPRO Composite, Tiredness, Cognitive Problems and Impaired Daylife scores showed a significant

Table 1 Characteristics of the study population. Values are presented as means ( \pm S.D.), medians (25-75 IQR) or as $n(\%)$.

\begin{tabular}{|c|c|}
\hline & $\begin{array}{c}\text { Total population } \\
\qquad(n=185)\end{array}$ \\
\hline Age at diagnosis (years) & $47.0 \pm 15.7$ \\
\hline Women & $131(71 \%)$ \\
\hline \multicolumn{2}{|l|}{ Disease type } \\
\hline Papillary thyroid cancer & $162(88 \%)$ \\
\hline Follicular thyroid cancer & $23(12 \%)$ \\
\hline \multicolumn{2}{|l|}{ ATA Risk Stratification System (2015) } \\
\hline Low risk & $72(39 \%)$ \\
\hline Intermediate risk & $55(30 \%)$ \\
\hline High risk & $58(31 \%)$ \\
\hline \multicolumn{2}{|l|}{ AJCC/TNM Staging system (8th edition) } \\
\hline Stage I & $138(75 \%)$ \\
\hline Stage II & $35(19 \%)$ \\
\hline Stage III & $9(5 \%)$ \\
\hline Stage IV & $3(2 \%)$ \\
\hline Surgery (TT) & $185(100 \%)$ \\
\hline Neck dissection & $70(38 \%)$ \\
\hline Central & $23(12 \%)$ \\
\hline Lateral & $1(1 \%)$ \\
\hline Both & $46(25 \%)$ \\
\hline RAl treatment & $185(100 \%)$ \\
\hline Once & $142(77 \%)$ \\
\hline Twice & $33(18 \%)$ \\
\hline$\geq 3$ & $10(5 \%)$ \\
\hline Withdrawal at first therapy & $154(83 \%)$ \\
\hline First dose (mCi) & $143(48-147)$ \\
\hline Admission duration first therapy (days) & $3(2-3)$ \\
\hline Cumulative dose (mCi) & $145(49-151)$ \\
\hline \multicolumn{2}{|l|}{ Hypoparathyroidism } \\
\hline Transient & $37(20 \%)$ \\
\hline Permanent & $31(17 \%)$ \\
\hline Recurrent nerve paralysis & $17(9 \%)$ \\
\hline Number of questionnaires per patient & $3(2-4)$ \\
\hline Follow-up (months) & $31(17-49)$ \\
\hline
\end{tabular}

$\mathrm{mCi}$, milliCurie; RAl; radioactive iodine; TT, total thyroidectomy. 
Table 2 Quality of life during follow-up.

\begin{tabular}{|c|c|}
\hline & Reference populations $(13,24,25)^{*}$ \\
\hline \multicolumn{2}{|l|}{ MFI-20 } \\
\hline General fatigue & $8.1 \pm 3.4$ \\
\hline Physical fatigue & $6.7 \pm 2.6$ \\
\hline Mental fatigue & $6.9 \pm 3.3$ \\
\hline \multicolumn{2}{|l|}{ RAND-36 } \\
\hline Vitality & $67.4 \pm 19.9$ \\
\hline $\begin{array}{l}\text { General Mental } \\
\text { Health }\end{array}$ & $76.8 \pm 18.4$ \\
\hline $\begin{array}{l}\text { General Health } \\
\text { Perception }\end{array}$ & $72.7 \pm 22.7$ \\
\hline Physical functioning & $81.9 \pm 23.2$ \\
\hline Social functioning & $86.9 \pm 20.5$ \\
\hline \multicolumn{2}{|l|}{ ThyPRO } \\
\hline Composite & na \\
\hline Tiredness & $35 \pm 21$ \\
\hline Cognitive problems & $14 \pm 17$ \\
\hline Anxiety & $13 \pm 16$ \\
\hline Depressivity & $21 \pm 18$ \\
\hline Social impairment & na \\
\hline Impaired daylife & na \\
\hline
\end{tabular}

\begin{tabular}{r}
\hline Baseline $^{\dagger}$ \\
\hline $12.5 \pm 0.4$ \\
$11.3 \pm 0.4$ \\
$10.9 \pm 0.4$ \\
\\
$56.6 \pm 1.9$ \\
$66.7 \pm 1.3$ \\
$57.9 \pm 1.4$ \\
$76.3 \pm 1.0$ \\
$66.9 \pm 2.8$ \\
\\
$28.3 \pm 1.7$ \\
$40.6 \pm 2.1$ \\
$9.4 \pm 1.1$ \\
$26.7 \pm 1.1$ \\
$23.9 \pm 1.1$ \\
$6.2 \pm 1.1$ \\
$10.5 \pm 1.2$
\end{tabular}

\begin{tabular}{c}
\hline Around RAI therapy \\
\hline \\
$14.7 \pm 0.4^{\ddagger}$ \\
$13.4 \pm 0.4^{\ddagger}$ \\
$12.3 \pm 0.4^{\ddagger}$ \\
$44.6 \pm 1.8^{\ddagger}$ \\
$67.0 \pm 1.3$ \\
$57.8 \pm 1.4$ \\
$68.3 \pm 1.0^{\ddagger}$ \\
$57.0 \pm 2.4^{\ddagger}$ \\
$34.2 \pm 1.8^{\ddagger}$ \\
$52.8 \pm 2.0^{\ddagger}$ \\
$19.4 \pm 1.1^{\ddagger}$ \\
$15.9 \pm 1.1^{\ddagger}$ \\
$22.0 \pm 1.1$ \\
$6.0 \pm 1.1$ \\
$26.7 \pm 1.1^{\ddagger}$ \\
\hline
\end{tabular}

\begin{tabular}{c}
\hline $\mathbf{2 4}$ months $^{\dagger}$ \\
\hline $13.2 \pm 0.4$ \\
$11.5 \pm 0.4$ \\
$11.6 \pm 0.4^{\ddagger}$ \\
\\
$53.9 \pm 1.8$ \\
$68.2 \pm 1.3$ \\
$57.4 \pm 1.4$ \\
$73.9 \pm 1.0$ \\
$70.1 \pm 2.7$ \\
$26.6 \pm 1.6$ \\
$41.6 \pm 2.0$ \\
$14.3 \pm 1.1^{\ddagger}$ \\
$13.6 \pm 1.1^{\ddagger}$ \\
$18.1 \pm 1.1^{\ddagger}$ \\
$5.3 \pm 1.1$ \\
$8.2 \pm 1.1$
\end{tabular}

\pm 48 months $^{\dagger}$

$13.1 \pm 0.4$

$11.3 \pm 0.4$

$11.3 \pm 0.4$

$54.3 \pm 1.8$

$69.3 \pm 1.5^{\ddagger}$

$56.9 \pm 1.7$

$75.5 \pm 1.0$

$70.5 \pm 2.8$

$25.8 \pm 1.6$

$42.0+2.1$

$14.4 \pm 1.1^{\ddagger}$

$12.9 \pm 1.1^{\ddagger}$

$18.0 \pm 1.1^{\ddagger}$

$4.7 \pm 1.1^{\ddagger}$

$7.5 \pm 1.1^{\ddagger}$

*Values are means ( \pm S.D.) obtained from reference populations $(13,24,25)$. ${ }^{\dagger}$ Values are means $\left( \pm\right.$ S.E.). ${ }^{\ddagger}$ Significantly different compared to baseline. na, not available; RAI, radioactive iodine.

non-linear development over time (Fig. 1). QoL was the lowest immediately after RAI therapy, and subsequently increased again toward baseline levels in the following years. Patients had significant more Cognitive Problems at end of follow-up compared to baseline, although the end of follow-up score was similar to the value of the general population. Further, anxiety was high at baseline, and thereafter decreased with a short temporal increase around 1 year, and it was significantly lower after 24 and 48 months ( $P<0.001$ compared to baseline). Depressivity and social Impairment complaints decreased almost linearly over time.

All three MFI-20 scores also showed a significant non-linear development over time (Fig. 2), with the lowest QoL short after RAI therapy. QoL four years later was not significantly different compared to baseline level.

The RAND-36 Vitality, and both the Physical and Social functioning scores also showed a significant nonlinear development over time (Fig. 3). Again, QoL is the lowest short after RAI therapy, and subsequently, increased in such a way that QoL after 2 to 3 years is not significantly different compared to baseline levels. General Mental Health increased linearly over time, and it was significantly better after 48 months than at baseline $(P=0.039)$. General Health Perception showed a slight decrease over time, but after 48 months it was not significantly lower than at baseline.

\section{Influencing factors}

Age, gender, persistent hypoparathyroidism and recurrent nerve paralysis affect several QoL scores in a way that older male patients without persistent hypoparathyroidism or without recurrent nerve paralysis had the best QoL (Table 3 and Supplementaty Table 2). Additionally, the number of RAI therapies significantly altered QoL development over time for the MFI-20 Mental and General fatigue, and for the ThyPRO Tiredness and Impaired Daylife scores, while gender significantly influenced this for the RAND36 Physical function, and the ThyPRO Cognitive Problems and Impaired Daylife scores (Supplementary Figs 1, 2 and 3). Age, Initial ATA Risk category, and neck dissection significantly influenced QoL development over time either in one or two QoL scores (Supplementary Figs 1, 2 and 3).

\section{Discussion}

This study shows that in patients with DTC who were treated with total thyroidectomy followed by RAI therapy, QoL in general develops non-linear over time. The lowest QoL was observed around RAI therapy, while afterward it took 2 to 3 years to return to baseline QoL levels. This is even despite the fact that QoL before initial therapy was already lower than that of the general population.

We showed a significant non-linear development of QoL over time in the majority of the measured QoL scales. 

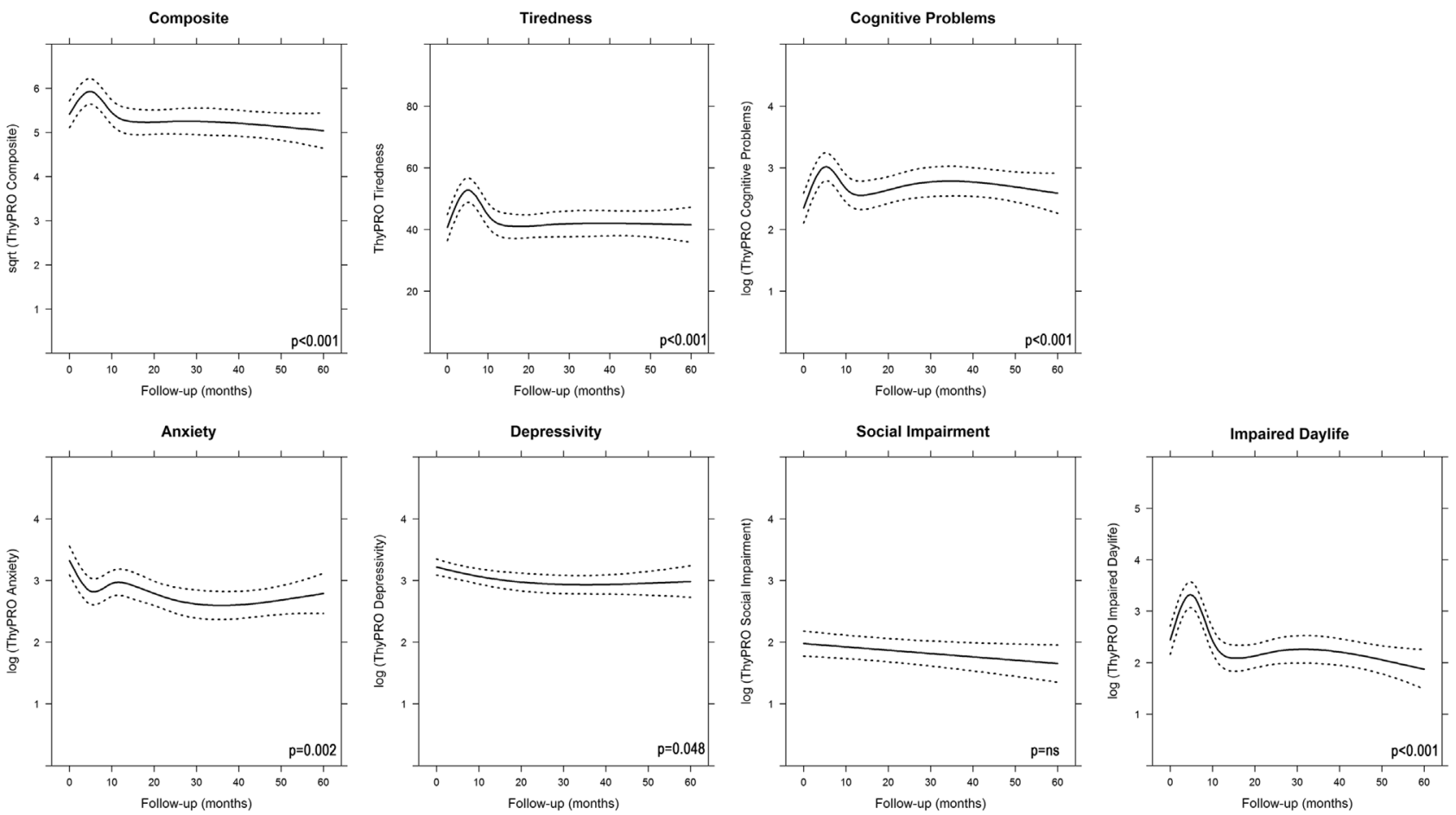

Figure 1

Quality of life over time for the different ThyPRO scores.

QoL was the lowest around RAI therapy, and afterward it took 2 to 3 years to return to baseline. This pattern of lowest QoL around RAI therapy, and thereafter increasing QoL was also shown by Gamper et al. (16). However, their study did not have data on QoL before surgery. Like in our study, at the end of follow-up, QoL was still lower than that in the general population. Lubitz et al. showed a temporary decrease of QoL after initial therapy, but after 6 months QoL was comparable to baseline (21); it must be noted that only half of their population received RAI therapy, and the majority of these patients received RAI therapy after preparation with rhTSH. Gou et al. (17) and Ryu et al. (19) showed a decreased QoL after initial therapy which thereafter increased again, but was still below baseline at the end of follow-up. Ryu et al. had a

follow-up of just 12 months so nothing was known about QoL evolution thereafter (19), while Gou et al. followed during 24 months thyroid cancer patients who did not received RAI therapy (17). Therefore, the decreased QoL after initial therapy in their study may have been due to postsurgical complaints and thereafter possibly due to fear of disease/recurrence. This study indicates that our finding of a decreased QoL around RAI therapy might to some extent also be partly explained by postsurgical complaints. Further, Ryu et al. showed that QoL after 12 months is better in patients who received a total thyroidectomy without RAI therapy, but nothing is known what happens thereafter (19). In combination with our results this suggests that less aggressive treatment might be favorable for QoL in the long term. We observed
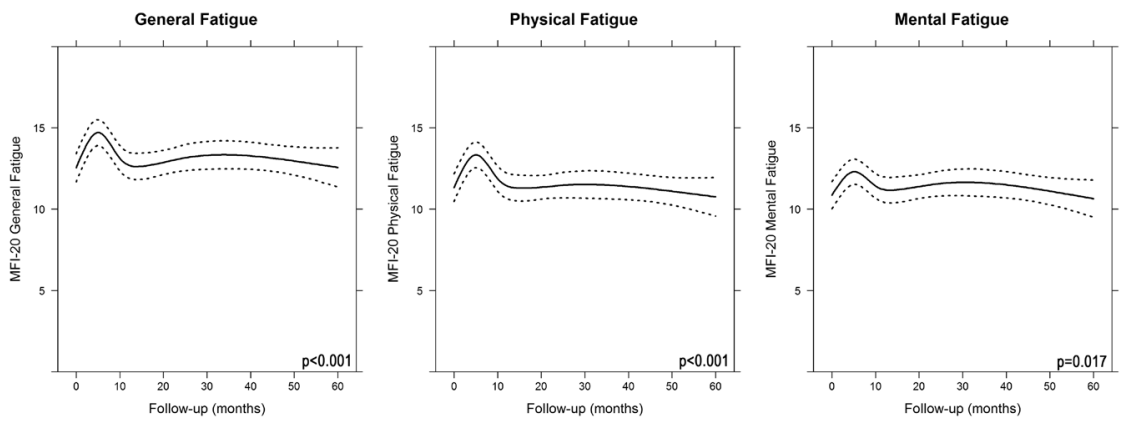

Figure 2

Quality of Life over time for the different MFI-20 scores. 

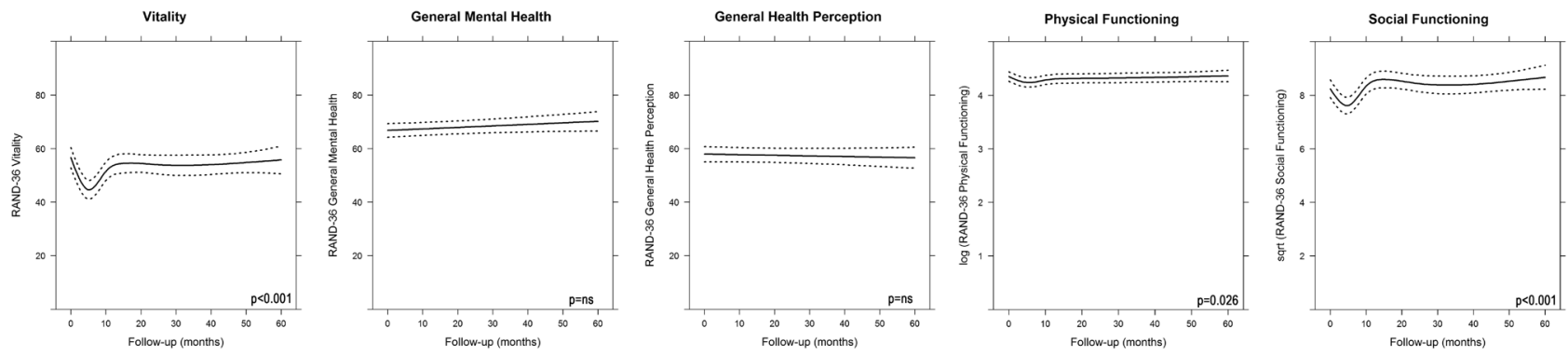

\section{Figure 3}

Quality of life over time for the different RAND-36 scores.

a different development over time with respect to the ThyPRO Anxiety score; it was the highest before initial therapy, and thereafter significantly decreased with a short temporal increase around approximately 1 year. This pattern is probably due to fear of the disease itself, and later-on of recurrence; this same pattern was also shown in another study (20).

We observed that QoL before initial therapy for all scores was lower in patients than reference values of the general population obtained from literature, except the ThyPRO Cognitive Problems Scale $(13,25,26)$. This might be due to the fact that patients already were aware of their thyroid cancer diagnosis when completing baseline questionnaires. Knowledge of QoL before initial treatment is important to differentiate between attribution to thyroid cancer and/or other diseases (e.g. cardiovascular) in patients with a decreased QoL years after diagnosis of the thyroid cancer. Unfortunately, it is impossible to have QoL scores of thyroid cancer patients before (suspicion of) diagnosis, so using reference values of the general population is second best. Lubitz et al. (21) and Ryu et al. (19) showed baseline QoL scores that were comparable with the general population, while Gou et al. (17) also showed a lower QoL at baseline. The persistent decreased QoL in our population 2 to 3 years after initial therapy, compared to the general population, might explain why earlier cross-sectional studies also found a lower QoL in thyroid cancer survivors compared to the general population (12, $13,14,15,16,17)$. In addition, earlier studies in patients with benign thyroid disease showed slightly lowered QoL scores in most domains before surgery, while results after surgery were mixed varying from normalization of QoL toward no significant change $(26,27,28)$. Therefore, it is possible that the decreased baseline QoL score in thyroid cancer patients might also be partly explained by fear of the upcoming therapy.

In a univariate analysis, younger age, female sex, and persistent hypoparathyroidism resulted in lower
QoL. These results are in line with earlier studies $(29,30)$. Persistent hypoparathyroidism resulting in lower QoL might also suggest that less aggressive treatment, if possible, might be favorable for QoL in the long term. We also observed that the QoL over time trajectories for patients receiving one or multiple RAI therapies were not significantly different, except for two MFI-20 and two ThyPRO scores. A difference between the two groups was expected, but due to the fact that the multiple RAI group is relatively small (23\%) and patients received additional therapies at different time points, their variations in QoL were probably compensated by the rest of the population having a 'normal' QoL at these time points.

Nine percent of our patients had a recurrent nerve paralysis at the end of follow-up. According to the 2015 ATA Guidelines, vocal cord paresis or paralysis can be present in up to $8 \%$ presurgically, and up to $30 \%$ of the patients postsurgically (6). Next to this, $17 \%$ of our patients obtained permanent hypoparathyroidism $30 \%$ in the neck dissection, and $9 \%$ in the group without neck dissection). Earlier studies showed percentages of permanent hypoparathyroidism up to $10 \%(6,31,32$, 33). However, thyroid cancer surgery and/or central neck dissection are known risk factors for developing hypoparathyroidism (6), and as $38 \%$ of patients in our tertiary referral center received a neck dissection already at initial therapy (2/3 with both central and lateral), this might be the reason for the higher percentage found in our study.

The main strength of this study is the relative large number of DTC patients that, starting before initial therapy, were followed longitudinally. Furthermore, our follow-up of more than 2.5 years (in $25 \%$ of our patients longer than 4 years) is relatively longer than earlier longitudinal studies with QoL assessment before initial therapy. Besides, using marginal models for repeatedmeasurement analysis, it is possible to create a model for QoL development over time, which enabled us to 
Table 3 Univariate analyses of factors influencing quality of life over time.

\begin{tabular}{|c|c|c|c|c|c|c|c|}
\hline & Age $^{*, t}$ & Gender*,* & $\begin{array}{c}\text { Number of RAI } \\
\text { therapies }\end{array}$ & $\begin{array}{l}\text { ATA risk } \\
\text { category }^{*}, \|\end{array}$ & $\begin{array}{c}\text { Persistent } \\
\text { hypoparathyroidism }{ }^{*}, \pi\end{array}$ & $\begin{array}{c}\text { Recurrent } \\
\text { nerve } \\
\text { paralysis }\end{array}$ & $\begin{array}{c}\text { Neck } \\
\text { dissection }\end{array}$ \\
\hline \multicolumn{8}{|l|}{ MFI-20 } \\
\hline General fatigue & 0.002 & $<0.0001$ & Interaction & 0.585 & 0.638 & 0.288 & 0.162 \\
\hline Physical fatigue & 0.121 & $<0.0001$ & 0.469 & 0.502 & 0.155 & 0.791 & 0.484 \\
\hline Mental fatigue & 0.012 & 0.020 & Interaction & Interaction & 0.110 & 0.077 & Interaction \\
\hline \multicolumn{8}{|l|}{ RAND-36 } \\
\hline Vitality & 0.025 & $<0.001$ & 0.705 & 0.505 & 0.257 & 0.379 & 0.169 \\
\hline $\begin{array}{l}\text { General Mental } \\
\text { Health }\end{array}$ & 0.019 & 0.011 & 0.119 & 0.743 & 0.318 & 0.758 & 0.601 \\
\hline $\begin{array}{l}\text { General Health } \\
\text { Perception }\end{array}$ & Interaction & 0.006 & 0.846 & 0.443 & 0.048 & 0.145 & 0.370 \\
\hline $\begin{array}{l}\text { Physical } \\
\text { functioning }\end{array}$ & 0.439 & Interaction & 0.359 & 0.508 & 0.003 & 0.147 & 0.813 \\
\hline Social functioning & 0.038 & 0.006 & 0.494 & 0.609 & 0.020 & 0.653 & 0.929 \\
\hline \multicolumn{8}{|l|}{ ThyPRO } \\
\hline Composite & 0.015 & 0.001 & 0.778 & 0.932 & 0.012 & 0.229 & 0.959 \\
\hline Tiredness & 0.075 & $<0.001$ & Interaction & Interaction & 0.034 & 0.971 & 0.227 \\
\hline $\begin{array}{l}\text { Cognitive } \\
\text { problems }\end{array}$ & 0.096 & Interaction & 0.756 & 0.707 & 0.258 & 0.551 & 0.751 \\
\hline Anxiety & 0.174 & 0.100 & 0.696 & 0.827 & 0.791 & 0.030 & 0.910 \\
\hline Depressivity & 0.024 & 0.006 & 0.176 & 0.594 & 0.220 & 0.021 & 0.945 \\
\hline Social impairment & $<0.001$ & 0.005 & 0.210 & 0.960 & 0.040 & 0.539 & 0.762 \\
\hline Impaired daylife & 0.115 & Interaction & Interaction & 0.395 & $<0.001$ & 0.964 & 0.287 \\
\hline
\end{tabular}

${ }^{\star} P$ values for influence on quality of life over time. ${ }^{\dagger}<50$ years vs $\geq 50$ years ( $<50$ years as reference group). ${ }^{\ddagger}$ Women vs men (women as reference group). ${ }^{5}$ Single vs multiple RAI therapies (single as reference group). "ATA Low vs High Risk (low as reference group). "Yes vs no (no as reference group).

Significant $P$-values $(<0.05)$ are presented in boldface.

determine QoL at each moment in time. Additionally, these models also enabled us to correct for missing QoL scores. A possible limitation of the study is that patients were recruited from a single tertiary university hospital, which attracts patients with more aggressive disease possibly leading into worsened QoL already at baseline. Next to this, as mentioned earlier, QoL scores before initial treatment are influenced by the fact that patients were already aware of their cancer diagnosis, which probably resulted into lower scores. However, it is impossible to know their QoL scores before (suspicion of) diagnosis. Also, it might be that QoL itself can contribute to the patient's tendency completing questionnaires. However, $84 \%$ of the included patients completed two or more questionnaires which is a decent percentage. Although being one of the largest prospective studies, we were unable to build a statistical model including all different studied factors to investigate a full model including all possible interactions between these studied factors. This is caused by the needed of non-linear terms in combination with the current sample size.

In conclusion, this study shows that in a population of DTC patients treated with total thyroidectomy and RAI therapy, QoL before initial therapy is already lower than that in the general population. Thereafter, QoL develops in general non-linear over time with the lowest QoL around RAI therapy, and 2 to 3 years after initial therapy, it is approximately the same as at baseline. Therefore, clinicians should be aware that it takes years to regain baseline QoL level after initial treatment with total thyroidectomy followed by RAI therapy. Herewith our results seem to support less aggressive treatment, but further longitudinal research, with follow-up of more than 5 years, also including patients who did not receive RAI therapy for DTC, is needed to know more about the QoL in the long term and the impact of less aggressive treatment on it.

\section{Supplementary data}

This is linked to the online version of the paper at https://doi.org/10.1530/ EJE-19-0550.

\section{Declaration of interest}

W Edward Visser is on the editorial board of EJE. W Edward Visser was not involved in the review or editorial process for this paper, on which he is listed as an author. The other authors have nothing to disclose.

\section{Funding}

This research did not receive any specific grant from any funding agency in the public, commercial or not-for-profit sector. 


\section{References}

1 La Vecchia C, Malvezzi M, Bosetti C, Garavello W, Bertuccio P, Levi F \& Negri E. Thyroid cancer mortality and incidence: a global overview. International Journal of Cancer 2015136 2187-2195. (https://doi.org/10.1002/ijc.29251)

2 Davies L \& Welch HG. Increasing incidence of thyroid cancer in the United States, 1973-2002. JAMA 2006295 2164-2167. (https://doi. org/10.1001/jama.295.18.2164)

3 van Velsen EFS, Stegenga MT, van Kemenade FJ, Kam BLR, van Ginhoven TM, Visser WE \& Peeters RP. Comparing the prognostic value of the eighth edition of the American Joint Committee on Cancer/Tumor Node Metastasis Staging system between papillary and follicular thyroid cancer. Thyroid 201828 976-981. (https://doi. org/10.1089/thy.2018.0066)

4 Pontius LN, Oyekunle TO, Thomas SM, Stang MT, Scheri RP, Roman SA \& Sosa JA. Projecting survival in papillary thyroid cancer: a comparison of the seventh and eighth editions of the American Joint Commission on Cancer/Union for International Cancer Control staging systems in two contemporary national patient cohorts. Thyroid 201727 1408-1416. (https://doi.org/10.1089/ thy.2017.0306)

5 Lundgren CI, Hall P, Ekbom A, Frisell J, Zedenius J \& Dickman PW. Incidence and survival of Swedish patients with differentiated thyroid cancer. International Journal of Cancer 2003106 569-573. (https://doi.org/10.1002/ijc.11275)

6 Haugen BR, Alexander EK, Bible KC, Doherty GM, Mandel SJ, Nikiforov YE, Pacini F, Randolph GW, Sawka AM, Schlumberger M et al. 2015 American Thyroid Association management guidelines for adult patients with thyroid nodules and differentiated thyroid cancer: the American Thyroid Association Guidelines task force on thyroid nodules and differentiated thyroid cancer. Thyroid 201626 1-133. (https://doi.org/10.1089/thy.2015.0020)

7 Luster M, Aktolun C, Amendoeira I, Barczynski M, Bible KC, Duntas LH, Elisei R, Handkiewicz-Junak D, Hoffmann M, Jarzab B et al. European perspective on 2015 American Thyroid Association Management Guidelines for adult patients with thyroid nodules and differentiated thyroid cancer: Proceedings of an Interactive International Symposium. Thyroid 201929 7-26. (https://doi. org/10.1089/thy.2017.0129)

8 Ware Jr JE \& Sherbourne CD. The MOS 36-item short-form health survey (SF-36). I. Conceptual framework and item selection. Medical Care 199230 473-483. (https://doi.org/10.1097/00005650199206000-00002)

9 McHorney CA, Ware Jr JE \& Raczek AE. The MOS 36-item short-form health survey (SF-36): II. Psychometric and clinical tests of validity in measuring physical and mental health constructs. Medical Care 1993 31 247-263. (https://doi.org/10.1097/00005650-199303000-00006)

10 Watt T, Barbesino G, Bjorner JB, Bonnema SJ, Bukvic B, Drummond R, Groenvold M, Hegedus L, Kantzer V, Lasch KE et al. Cross-cultural validity of the thyroid-specific quality-of-life patientreported outcome measure, ThyPRO. Quality of Life Research 201524 769-780. (https://doi.org/10.1007/s11136-014-0798-1)

11 Watt T, Cramon P, Hegedus L, Bjorner JB, Bonnema SJ, Rasmussen ÅK, Feldt-Rasmussen U \& Groenvold M. The thyroidrelated quality of life measure ThyPRO has good responsiveness and ability to detect relevant treatment effects. Journal of Clinical Endocrinology and Metabolism 201499 3708-3717. (https://doi. org/10.1210/jc.2014-1322)

12 Massolt ET, van der Windt M, Korevaar TI, Kam BL, Burger JW, Franssen GJ, Lehmphul I, Kohrle J, Visser WE \& Peeters RP. Thyroid hormone and its metabolites in relation to quality of life in patients treated for differentiated thyroid cancer. Clinical Endocrinology 2016 85 781-788. (https://doi.org/10.1111/cen.13101)

13 Hoftijzer HC, Heemstra KA, Corssmit EP, van der Klaauw AA, Romijn JA \& Smit JW. Quality of life in cured patients with differentiated thyroid carcinoma. Journal of Clinical Endocrinology and Metabolism 200893 200-203. (https://doi.org/10.1210/jc.2007-1203)

14 Singer S, Lincke T, Gamper E, Bhaskaran K, Schreiber S, Hinz A \& Schulte T. Quality of life in patients with thyroid cancer compared with the general population. Thyroid 201222 117-124. (https://doi. org/10.1089/thy.2011.0139)

15 Husson O, Haak HR, Buffart LM, Nieuwlaat WA, Oranje WA, Mols F, Kuijpens JL, Coebergh JW \& van de Poll-Franse LV. Health-related quality of life and disease specific symptoms in long-term thyroid cancer survivors: a study from the population-based PROFILES registry. Acta Oncologica 201352 249-258. (https://doi.org/10.3109/ 0284186X.2012.741326)

16 Gamper EM, Wintner LM, Rodrigues M, Buxbaum S, Nilica B, Singer S, Giesinger JM, Holzner B \& Virgolini I. Persistent quality of life impairments in differentiated thyroid cancer patients: results from a monitoring programme. European Journal of Nuclear Medicine and Molecular Imaging 201542 1179-1188. (https://doi.org/10.1007/ s00259-015-3022-9)

17 Gou J, Cheng W, Lei J, Pan Q, You W, Cai M, Tang H, Lei Y, Li Z, Gong R et al. Health-related quality-of-life assessment in surgical patients with papillary thyroid carcinoma: a single-center analysis from Mainland China. Medicine 201796 e8070. (https://doi. org/10.1097/MD.0000000000008070)

18 Applewhite MK, James BC, Kaplan SP, Angelos P, Kaplan EL, Grogan RH \& Aschebrook-Kilfoy B. Quality of life in thyroid cancer is similar to that of other cancers with worse survival. World Journal of Surgery 201640 551-561. (https://doi.org/10.1007/s00268-015-3300-5)

19 Ryu CH, Park B, Ryu J, Ryu YM, Jo SA, Lee YJ, Lee EK, Hwangbo Y, Joo J \& Jung YS. Development and evaluation of a Korean version of a thyroid-specific quality-of-life questionnaire scale in thyroid cancer patients. Cancer Research and Treatment 201850 405-415. (https:// doi.org/10.4143/crt.2017.012)

20 Hedman C, Djarv T, Strang P \& Lundgren CI. Fear of recurrence and view of life affect health-related quality of life in patients with differentiated thyroid carcinoma: a prospective Swedish populationbased study. Thyroid 201828 1609-1647. (https://doi.org/10.1089/ thy.2018.0388)

21 Lubitz CC, De Gregorio L, Fingeret AL, Economopoulos KP, Termezawi D, Hassan M, Parangi S, Stephen AE, Halpern EF, Donelan $\mathrm{K}$ et al. Measurement and variation in estimation of quality of life effects of patients undergoing treatment for papillary thyroid carcinoma. Thyroid 201727 197-206. (https://doi.org/10.1089/ thy.2016.0260)

222015 Dutch Thyroid Cancer Guidelines, 2015 [updated 2015-02-16]. (available at: https://www.oncoline.nl/schildkliercarcinoom)

23 Watt T, Bjorner JB, Groenvold M, Cramon P, Winther KH, Hegedus L, Bonnema SJ, Rasmussen ÅK, Ware Jr JE \& Feldt-Rasmussen U. Development of a short version of the thyroid-related patientreported outcome ThyPRO. Thyroid 201525 1069-1079. (https://doi. org/10.1089/thy.2015.0209)

24 Smets EM, Garssen B, Bonke B \& De Haes JC. The multidimensional fatigue inventory (MFI) psychometric qualities of an instrument to assess fatigue. Journal of Psychosomatic Research 199539 315-325. (https://doi.org/10.1016/0022-3999(94)00125-o)

25 VanderZee KI, Sanderman R, Heyink JW \& de Haes H. Psychometric qualities of the rand 36-item health survey 1.0: a multidimensional measure of general health status. International Journal of Behavioral Medicine 19963 104-122. (https://doi.org/10.1207/ s15327558ijbm0302_2)

26 Cramon P, Bonnema SJ, Bjorner JB, Ekholm O, Feldt-Rasmussen U, Frendl DM, Groenvold M, Hegedus L, Rasmussen ÅK \& Watt T. Quality of life in patients with benign nontoxic goiter: impact of disease and treatment response, and comparison with the general population. Thyroid 201525 284-291. (https://doi.org/10.1089/thy.2014.0433)

27 Sorensen JR, Watt T, Cramon P, Dossing H, Hegedus L, Bonnema SJ $\&$ Godballe C. Quality of life after thyroidectomy in patients with 
nontoxic nodular goiter: a prospective cohort study. Head and Neck 201739 2232-2240. (https://doi.org/10.1002/hed.24886)

28 Dulfer R, Geilvoet W, Morks A, van Lieshout EM, Smit CP, Nieveen van Dijkum EJ, In't Hof K, van Dam F, van Eijck CH, de Graaf PW et al. Impact of parathyroidectomy for primary hyperparathyroidism on quality of life: a case-control study using short form health survey 36. Head and Neck 201638 1213-1220. (https://doi.org/10.1002/ hed.24499)

29 Aschebrook-Kilfoy B, James B, Nagar S, Kaplan S, Seng V, Ahsan H, Angelos P, Kaplan EL, Guerrero MA, Kuo JH et al. Risk factors for decreased quality of life in thyroid cancer survivors: initial findings from the North American thyroid cancer survivorship study. Thyroid 201525 1313-1321. (https://doi.org/10.1089/thy.2015.0098)

30 Lorente-Poch L, Sancho JJ, Carballo L \& Sitges-Serra A. Clinical profile and long-term follow-up of 32 patients with postoperative permanent hypoparathyroidism. Gland Surgery 20176 (Supplement 1) S3-S10. (https://doi.org/10.21037/gs.2017.11.10)

31 Chadwick DR. Hypocalcaemia and permanent hypoparathyroidism after total/bilateral thyroidectomy in the BAETS Registry. Gland Surgery 20176 (Supplement 1) S69-S74. (https://doi.org/10.21037/ gs.2017.09.14)

32 Orloff LA, Wiseman SM, Bernet VJ, Fahey 3rd TJ, Shaha AR, Shindo ML, Snyder SK, Stack Jr BC, Sunwoo JB \& Wang MB. American Thyroid Association statement on postoperative hypoparathyroidism: diagnosis, prevention, and management in adults. Thyroid 201828 830-841. (https://doi.org/10.1089/ thy.2017.0309)

33 Ahn HS, Kim HJ \& Welch HG. Korea's thyroid-cancer 'epidemic' screening and overdiagnosis. New England Journal of Medicine 2014 371 1765-1767. (https://doi.org/10.1056/NEJMp1409841)
Received 17 July 2019

Revised version received 19 October 2019

Accepted 22 October 2019 